\title{
Optimization of friction STIR welded AA6061 + SiCp metal matrix composite to increase joint tensile strength and reduce defects
}

\author{
N. Dilip Raja ${ }^{1{ }^{*}}$ (D) and R. Naren Shankar $^{2}$ (D) \\ ${ }^{1}$ Department of Mechanical Engineering, Vel Tech Rangarajan Dr. Sagunthala R\&D Institute of Science and Technology, \\ Avadi, Chennai 600062, Tamil Nadu, India \\ 2 Department of Aeronautical Engineering, Vel Tech Rangarajan Dr. Sagunthala R\&D Institute of Science and Technology, \\ Avadi, Chennai 600062, Tamil Nadu, India
}

Received: 10 April 2021 / Accepted: 14 October 2021

\begin{abstract}
Friction stir welding has been used in automobiles, locomotive, and aircraft structures. This metal joining process exhibits defects like kissing bonds, micropores, and tunnels. Factors like the joining material, joint thickness, tool geometry, and operating parameters control the defects in friction stir welding. The parameters like tool rotation, tool pass speed, and tool force have a greater influence on the joint quality. In this study, these parameters are considered to augment the strength of the joint and minimize defects. The metal matrix composite consisting of AA6061 matrix and $10 \mathrm{wt} . \% \mathrm{SiC}_{\mathrm{p}}$ reinforcement is joined used $\mathrm{FSW}$. The weld parameters were varied between 731 and $1068 \mathrm{rpm}$ tool rotation speed, 0.33 and $1.17 \mathrm{~mm} / \mathrm{s}$ tool pass speed, and 11 and $28 \mathrm{MPa}$ tool force. The joint strength varied from $165 \mathrm{MPa}$ to $244 \mathrm{MPa}$. The numerical analysis using ANOVA revealed that compared between the three parameters, the tool force had greater control over the tensile strength of the joint. After optimization, the joint was made at a tool rotation speed of $910 \mathrm{rpm}$, tool pass speed of $0.77 \mathrm{~mm} / \mathrm{s}$, and tool force of 22.33 MPa. The tensile strength increased to $249 \mathrm{MPa}$ after using the optimized weld parameters. The number of defects in the joint was reduced after using the optimized weld parameters.
\end{abstract}

Keywords: Friction stir welding / metal matrix composite / optimized weld parameters / joint strength / weld defects

\section{Introduction}

Ever since its discovery in 1991 by The Welding Institute, UK, the solid-state metal joining process called the Friction Stir Welding (FSW) has gained recognition as a versatile metal joining process [1]. It is employed in joining metals having varying properties like melting point, strength, and thermal conductivity. FSW can also join alloys and composite materials [2]. Its versatility has made it a preferred joining process in industrial and scientific sectors [3]. Aluminum alloys and their composites are used in commercial materials like automobile wheels, bicycles, sports watch, building panels, and industrial components like aircraft, marine structures, locomotive bodies, and boiler shells [4-10]. Incorporating silicon carbide particulates into the aluminum alloy enhances the tensile strength, hardness, impact strength, and corrosion resistance [11-15].

Composites of aluminum can be joined using FSW. However, factors such as the thickness of the material, the

\footnotetext{
* e-mail: rnarenshankar@gmail.com
}

composition of the reinforcement material, geometry of the reinforcement used, tool material, the geometry of the tool, welding parameters, and ambient condition play an important role in the quality of the joints produced using FSW [16-20]. Figure 1 shows the FSW welding parameters. The quality of the welded joint is determined by the strength exhibited by the joint. FSW joints exhibit defects like cracks, kissing bonds, tunnels, and porosity [10,21-25]. The presence of defects in the joint can reduce the joint quality.

Selection of optimum parameters for the FSW through the experimental approach using the trial and error method is a difficult task. The numerical approach reduces the time and cost involved in determining optimized parameters, while simultaneously increasing the accuracy of the predicted parameters [26]. Optimization tools like ANOVA can provide dependable values that can be used to obtained FSW joints with enhanced strength and reduced defects. In this study, optimization of the FSW parameters is carried out on the Metal Matrix Composite (MMC) containing AA6061 as matrix element and 10 wt.\% of Silicon Carbide particulates $(\mathrm{SiCp})$ as the reinforcement. Tool rotation, tool pass speed, and tool force were selected as the 


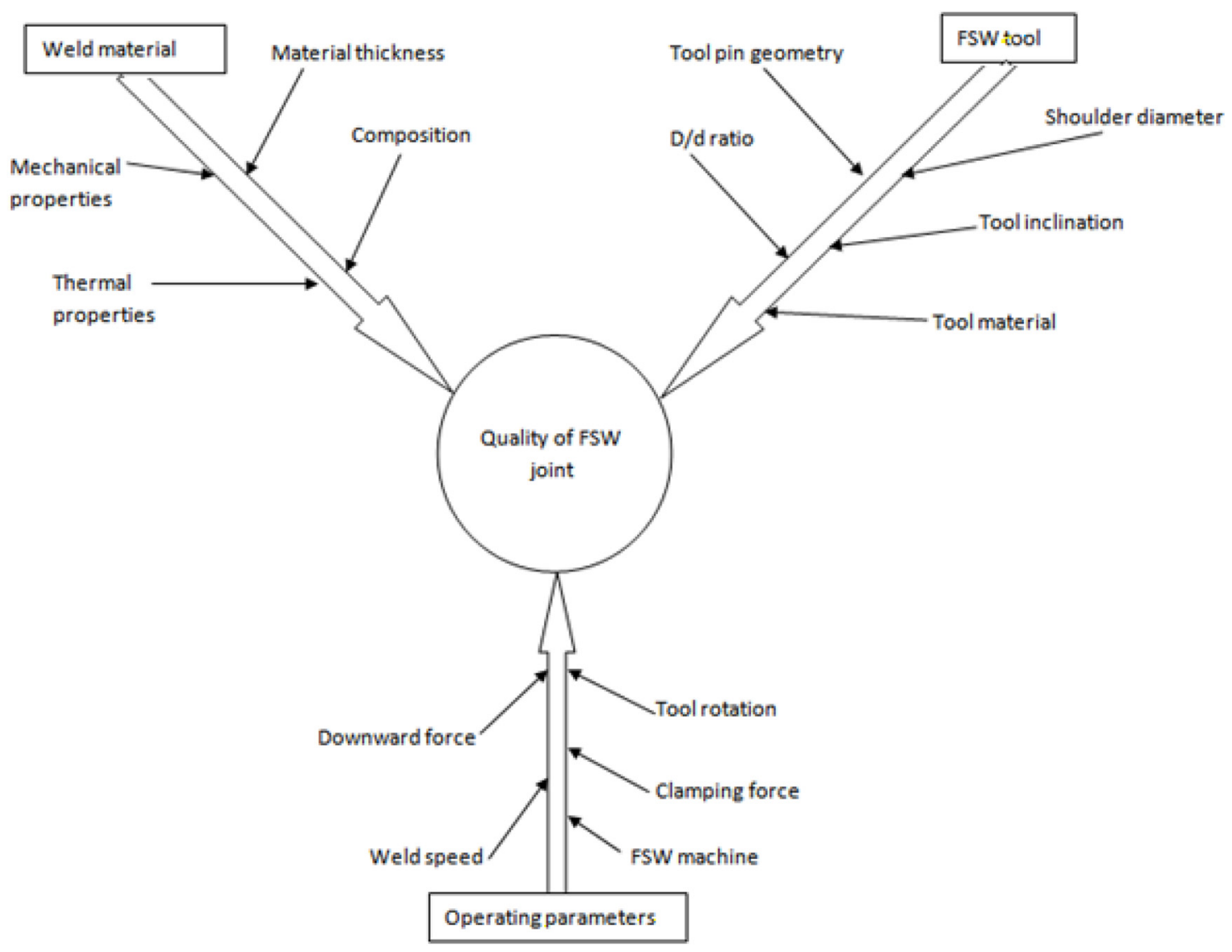

Fig. 1. FSW parameters influencing joint quality.

parameters for optimization using ANOVA. The parameters are optimized to augment the tensile strength of the FSW joints and also reduce the defects in the joint.

\section{Experimental work}

Experimental investigation of FSW was carried out in butt joint configuration on the MMC containing $10 \mathrm{wt} . \%$ of $\mathrm{SiCp}$ reinforcement particulates in the AA6061 matrix [12]. Hardened steel EN08 was selected as the material for the non-consumable tool to making the joint. A square pin profile with a $D / d$ ratio of $3: 1$ (where ' $D$ ' is the shoulder diameter of the tool and ' $d$ ' is the tool pin diameter) was selected for the tool because of its ability to produce joints with minimal defects [27].

The joints were made using an indigenously developed FSW machine in Vel Tech Multi Tech Engineering College, Chennai, Tamil Nadu, India. The machine specification included: $\quad 730-1070 \mathrm{rpm}$ spindle speed (clockwise), $0.30-1.20 \mathrm{~mm} / \mathrm{s}$ tool pass speed, and 10-30 MPa resultant force on the tool. Fifteen experimental runs were made using different combinations of the weld parameters mentioned above. Tensile strength of the FSW specimen was found using Universal Testing Machine (UTM) (FIE-Blue Star, India; Cap. 0-100KN, Model: Instron-UNITEK-94100). The test specimen was made as per ASTM E8M-04 standard. Table 1 shows the tensile strength of the FSW joint obtained from the fifteen runs. The combinations of parameters: $900 \mathrm{rpm}, 0.75 \mathrm{~mm} / \mathrm{s}$, and $20 \mathrm{MPa}$ developed the highest tensile strength of $244 \mathrm{MPa}$. Hence, the set parameters were repeated five times to get the following readings: $249,246,247,248$, and $252 \mathrm{MPa}$ respectively.

\section{Optimization technique}

Few research articles show the relevance of optimization in the study of welding parameters and its effect on joint quality $[28,29]$. In this study, the optimization was carried out in an attempt to reduce the defects while enhancing the tensile strength in the FSW joint. Design of Experiment (DOE) approach using Central Composite Design (CCD) was used for the optimization. The feasible working limits for the three FSW parameters were set as shown in Table 2. The CCD had five level factorial design clustered into three groups, i.e., eight design points, six-star points, and six center points as shown in Table 3. The five levels were subsequently denoted as: $-1.68,-1,0,1,1.68$ respectively.

\subsection{Development of empirical relationship to predict the maximum strength of joint}

Optimization of the FSW parameters was carried out to get joints with minimal defects. Equation (1) shows the relationship between the tensile strength of the FSW joint and the three parameters considered for the optimization. The second-order polynomial equation was used while 
Table 1. Tensile strength obtained from the MMC.

\begin{tabular}{lllll}
\hline S. no. & Tool rotation speed $(\mathrm{rpm})$ & Tool pass speed $(\mathrm{mm} / \mathrm{s})$ & Tool force $(\mathrm{MPa})$ & Tensile strength $(\mathrm{MPa})$ \\
\hline 1 & 800 & 0.5 & 15 & 165 \\
2 & 1000 & 0.5 & 15 & 185 \\
3 & 800 & 1 & 15 & 177 \\
4 & 1000 & 1 & 15 & 187 \\
5 & 800 & 0.5 & 25 & 198 \\
6 & 1000 & 0.5 & 25 & 192 \\
7 & 800 & 1 & 25 & 203 \\
8 & 1000 & 1 & 25 & 189 \\
9 & 731 & 0.75 & 20 & 175 \\
10 & 1068 & 0.75 & 20 & 178 \\
11 & 900 & 0.33 & 20 & 184 \\
12 & 900 & 1.17 & 20 & 192 \\
13 & 900 & 0.75 & 11 & 196 \\
14 & 900 & 0.75 & 28 & 226 \\
15 & 900 & 0.75 & 20 & 244 \\
\hline
\end{tabular}

Table 2. Feasible working limits of FSW parameters.

\begin{tabular}{llllllll}
\hline Parameters & Notations & Units & \multicolumn{5}{c}{ Levels } \\
\cline { 5 - 8 } & & & -1.68 & $(-1)$ & $(0)$ & $(+1)$ & +1.68 \\
\hline Rotational speed of tool & $\mathrm{A}$ & $\mathrm{rpm}$ & 731.00 & 800.00 & 900.00 & 1000.00 & 1068.00 \\
Tool pass speed & $\mathrm{B}$ & $\mathrm{mm} / \mathrm{s}$ & 0.33 & 0.50 & 0.75 & 1.00 & 1.17 \\
Tool force & $\mathrm{C}$ & $\mathrm{MPa}$ & 11.00 & 15.00 & 20.00 & 25.00 & 28.00 \\
\hline
\end{tabular}

determining the joint strength as shown in equation (2).

$$
\begin{gathered}
\mathrm{TS}=\mathrm{f}\{\mathrm{A}, \mathrm{B}, \mathrm{C}\} \\
\mathrm{TS}=\mathrm{b}_{0}+\mathrm{b}_{1}(\mathrm{~A})+\mathrm{b}_{2}(\mathrm{~B})+\mathrm{b}_{3}(\mathrm{C})+\mathrm{b}_{12}(\mathrm{~A} . \mathrm{B}) \\
+\mathrm{b}_{13}(\mathrm{~B} . \mathrm{C})+\mathrm{b}_{23}(\mathrm{~A} . \mathrm{C})+\mathrm{b}_{11}\left(\mathrm{~A}^{2}\right) \\
+\mathrm{b}_{22}\left(\mathrm{~B}^{2}\right)+\mathrm{b}_{33}\left(\mathrm{C}^{2}\right)
\end{gathered}
$$

where TS is the tensile strength of the joint, $b_{0}$ is the average of the response values, and $b_{1}, b_{2}, b_{3} \ldots b_{33}$ are regression coefficients which depends on factors like linear movement, interactive forces, and the respective squared terms.

Equation (3) shows the final empirical relationship for the desired tensile strength of the FSW joint produced on the MMC.

$$
\begin{aligned}
\mathrm{TS}= & 247.71+1.10 \mathrm{~A}+2.16 \mathrm{~B}+8.67 \mathrm{C}-2.25 \mathrm{~A} . \mathrm{B} \\
& -6.25 \mathrm{~B} . \mathrm{C}-1.50 \mathrm{~A} . \mathrm{C}-25.47 \mathrm{~A}^{2}-21.40 \mathrm{~B}^{2} \\
& -13.27 \mathrm{C}^{2}
\end{aligned}
$$

\subsection{ANOVA analysis}

The CCD was carried out with the help of ANOVA. Table 4 shows the goodness of fit, that was found to ensure that the input parameters, i.e., tool rotation speed, tool pass speed, and tool force were consistent between the actual and predicted values. The goodness of fit is the statistical tool that is used to check whether the sample data from the population distribution fit with the normal distribution. The coefficient of variation (C.V.\%) of $1.04 \%$, suggests good precision and reliability required for carrying out the optimization. The Predicted Residual Error Sum of Squares (PRESS) is determined by multiplying 100 to the ratio of the standard deviation and the mean. The goodness of fit showed adequacy in precision greater than 54 .

\section{Result and discussion}

\subsection{Experimental investigation}

The quality of the FSW joints produced on the MMCs was visually examined as shown in Figure 2. Comparative analysis was made by varying the parameters used to make 
Table 3. ANOVA analysis using a central composite design.

\begin{tabular}{llllll}
\hline Standard order & Run order & \multicolumn{3}{c}{ Coded value } & Tensile strength (MPa) \\
\cline { 3 - 5 } & & $\mathrm{A}$ & $\mathrm{B}$ & $\mathrm{C}$ & \\
\hline 1 & 12 & -1 & -1 & -1 & 165.00 \\
2 & 2 & 1 & -1 & -1 & 185.00 \\
3 & 4 & -1 & 1 & -1 & 177.00 \\
4 & 20 & 1 & 1 & -1 & 187.00 \\
5 & 9 & -1 & -1 & 1 & 198.00 \\
6 & 1 & 1 & -1 & 1 & 192.00 \\
7 & 17 & -1 & 1 & 1 & 203.00 \\
8 & 6 & 1 & 1 & 1 & 189.00 \\
9 & 7 & -1.68 & 0 & 0 & 175.00 \\
10 & 13 & 1.68 & 0 & 0 & 178.00 \\
11 & 10 & 0 & -1.68 & 0 & 184.00 \\
12 & 3 & 0 & 1.68 & 0 & 192.00 \\
13 & 15 & 0 & 0 & -1.68 & 196.00 \\
14 & 5 & 0 & 0 & 1.68 & 226.00 \\
15 & 19 & 0 & 0 & 0 & 244.00 \\
16 & 11 & 0 & 0 & 0 & 249.00 \\
17 & 18 & 0 & 0 & 0 & 246.00 \\
18 & 8 & 0 & 0 & 0 & 247.00 \\
19 & 14 & 0 & 0 & 0 & 248.00 \\
20 & 16 & 0 & 0 & 0 & 252.00 \\
\hline
\end{tabular}

Table 4. Goodness of fit.

\begin{tabular}{ll}
\hline Standard Deviation & 2.15 \\
\hline Mean value & 206.66 \\
C.V. \% & 1.05 \\
PRESS. & 119.97 \\
$R^{2}$ & 0.99732 \\
Adj. $R^{2}$ & 0.9947 \\
Pred. $R^{2}$ & 0.9931 \\
Adequate Precision & 54.115 \\
\hline
\end{tabular}

the FSW joints. When the input parameters were low, i.e., the tool rotation speed of $731 \mathrm{rpm}$, tool pass speed of $0.75 \mathrm{~mm} / \mathrm{s}$, and tool force of $20 \mathrm{MPa}$, the frictional heat required to plasticize the weldment was insufficient. The onion rings over the surface of the joint were observed as the material transfer was initiated by the non-consumable tool. However, the insufficient frictional heat restricted the weldment to reach the retreating side. As the result, metal protrusion occurred along the advancing side. The onion rings thus formed were uneven along the joint as shown in Figure 2a.

When the input parameters were low, i.e., the tool rotation speed of $1068 \mathrm{rpm}$, tool pass speed of $0.75 \mathrm{~mm} / \mathrm{s}$, and tool force of $20 \mathrm{MPa}$, frictional heat on the weldment was in excess. As the result, the weld region below the tool shoulder expanded, leading to the transfer of weldment to reach the retreating side and further travel to the advancing side. Hence, onion rings did not form over the FSW as shown in Figure 2b. Protrusion of the weld metal was observed on both sides of the weld joint, indicating that the weldment made excess movement during the FSW process.

For the tool rotation speed of $900 \mathrm{rpm}$, tool pass speed of $0.33 \mathrm{~mm} / \mathrm{s}$, and tool force of $20 \mathrm{MPa}$, the frictional heat was sufficient to plasticize the matrix element in the MMC. However, the low pass speed of the tool leads to the excess transfer of weldment from the advancing side to the retreating side. The excess material then protruded along the advancing side as shown in Figure 2c. The transition of weldment from the retreating side and back to the advancing side resulted in the onion rings occurring fairly close to each other.

For the tool rotation speed of $900 \mathrm{rpm}$, tool pass speed of $1.17 \mathrm{~mm} / \mathrm{s}$, and tool force of $20 \mathrm{MPa}$, the frictional heat developed during the joining process was sufficient to plasticize the matrix of the MMC. However, the tool moved relatively fast, leading to excess deposition of weldment along the retreating side as shown in Figure 2d. This caused the FSW joint to have an unsymmetrical and stretched-out region along the retreating side. The distorted appearance of the weld pin indentation in the FSW joint indicates that the sharp edges of the tool caused the pulsed transfer of the weldment.

For the tool rotation speed of $900 \mathrm{rpm}$, tool pass speed of $0.75 \mathrm{~mm} / \mathrm{s}$, and tool force of $11 \mathrm{MPa}$, the relatively low tool force greatly reduced the frictional heat necessary to plasticize the matrix element of the MMC. Sufficient heat 


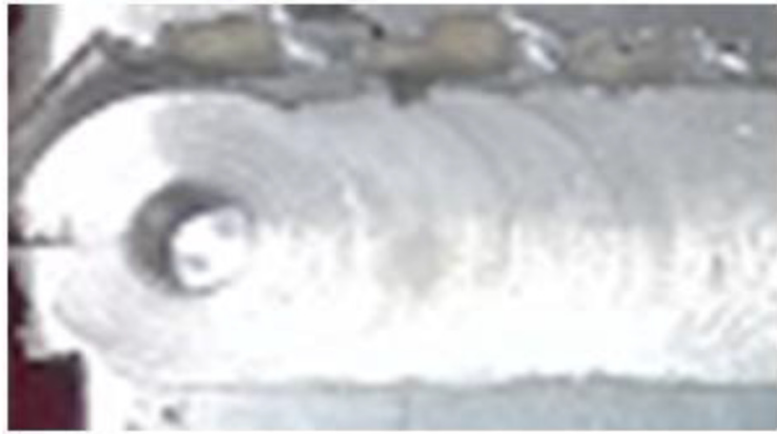

(a)

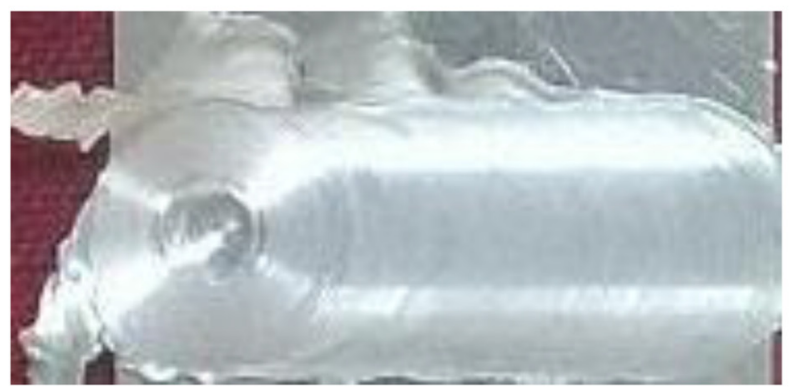

(c)

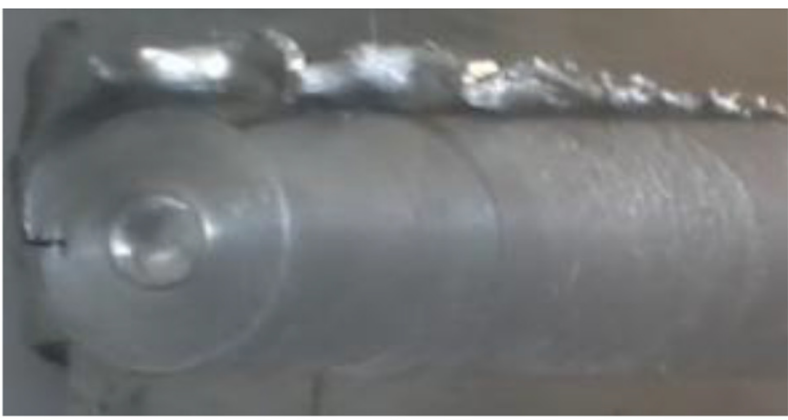

(e)

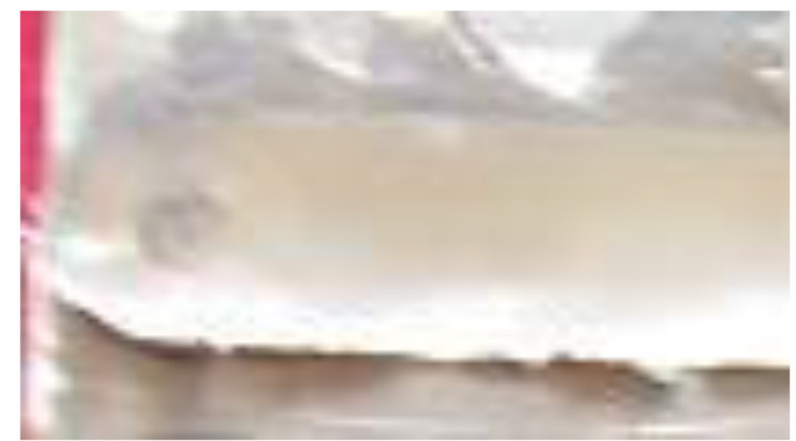

(b)

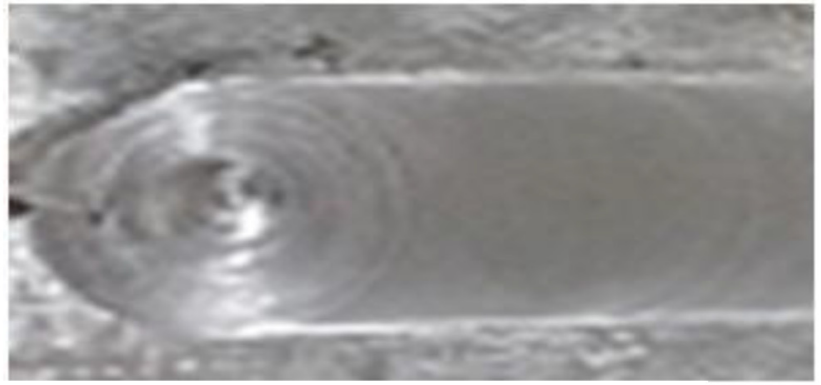

(d)

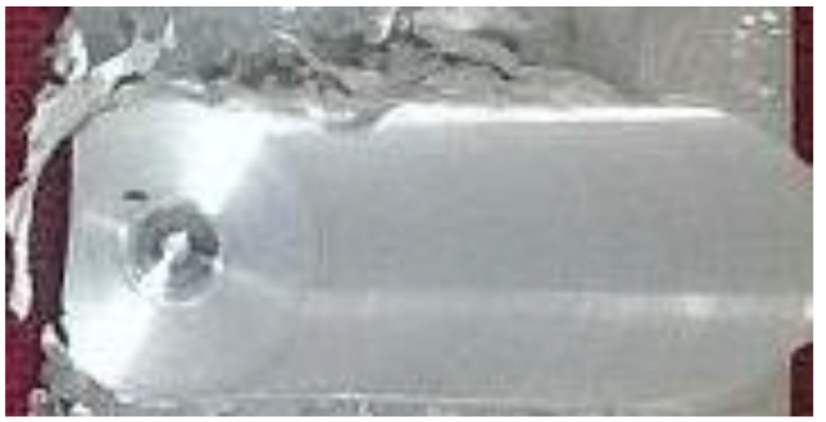

(f)

Fig. 2. The surface state of some obtained joints using varying parameters in FSW. (a) $731 \mathrm{rpm}$ tool rotation speed. (b) $1068 \mathrm{rpm}$ tool rotation speed. (c) $0.33 \mathrm{~mm} / \mathrm{s}$ tool pass speed. (d) $1.17 \mathrm{~mm} / \mathrm{s}$ tool pass speed. (e) $11 \mathrm{MPa}$ tool force. (f) $28 \mathrm{MPa}$ tool force.

energy required to plasticize the materials was provided by the tool pin. However, it leads to improper transfer of weldment from the advancing side to the retreating side. This was because the tool shoulder did not supply the required friction to heat and plasticize the material below it. Metal protrusion occurred along the advancing side and the onion rings were observed at disproportional intervals along the produced FSW joint as shown in Figure 2e.

For the tool rotation speed of $900 \mathrm{rpm}$, tool pass speed of $0.75 \mathrm{~mm} / \mathrm{s}$, and tool force of $28 \mathrm{MPa}$, the tool force was in excess. This resulted in increased frictional heat generated by the tool shoulder over the surface of the joining material. The excessive tool force plunged the tool shoulder into the weldment as shown in Figure 2f. The excessive frictional heat increased the plasticized region below the tool shoulder, resulting in the transfer of material to the retreating side and back to the advancing side. This caused the metal protrusion to occur along both sides of the joint.

\subsection{Numerical Investigation}

The results obtained during the numerical analysis using ANOVA are provided in Table 5 . The ratio between the maximum and minimum tensile strength of the FSW joint was 1.52727 . Because of this, the analysis was not subjected to transformation. As desired for the analysis, the probability value was greater than the $F$ value. This indicates that the model that is considered for the analysis is significant. Likewise, the interaction effect between the FSW parameters was also significant. However, the Lack of Fit was non-significant as desirable for the ANOVA.

The response surfaces were used to infer the result obtained during the numerical investigation. The numerical analysis was carried out by keeping one of the input parameters, i.e., tool rotation speed, tool pass speed, and tool force as constant while varying the other two parameters. The influence of the three parameters on the 
Table 5. Numerical results.

\begin{tabular}{llllll}
\hline Source & Sum of Squares & df & Mean square & $F$ value & Prob $>F$ \\
\hline Model & 17205.56 & 9 & 1912.85 & 415.66 & $<0.0001$ (significant) \\
A-Tool Rotation Speed & 15.59 & 1 & 15.59 & 3.61 & 0.0869 \\
B-Tool Pass Speed & 62.55 & 1 & 62.55 & 14.80 & 0.0041 \\
C-Tool Force & 1028.44 & 1 & 1028.44 & 222.38 & $<0.0001$ \\
A.B & 41.51 & 1 & 41.51 & 8.81 & 0.0142 \\
A.C & 313.51 & 1 & 313.51 & 68.95 & $<0.0001$ \\
B.C & 19.02 & 1 & 19.02 & 3.90 & 0.0762 \\
A $^{2}$ & 9347.31 & 1 & 9347.31 & 2032.95 & $<0.0001$ \\
B $^{2}$ & 6601.15 & 1 & 6601.15 & 1435.92 & $<0.0001$ \\
C $^{2}$ & 2536.27 & 1 & 2536.27 & 550.63 & $<0.0001$ \\
Residual & 45.01 & 10 & 4.61 & & 0.24 \\
Lack of Fit & 8.56 & 5 & 1.74 & 7.48 & 0.9327 (not significant) \\
Pure Error & 38.34 & 5 & 19 & & \\
Cor. Total & 17253.56 & & & & \\
\hline
\end{tabular}

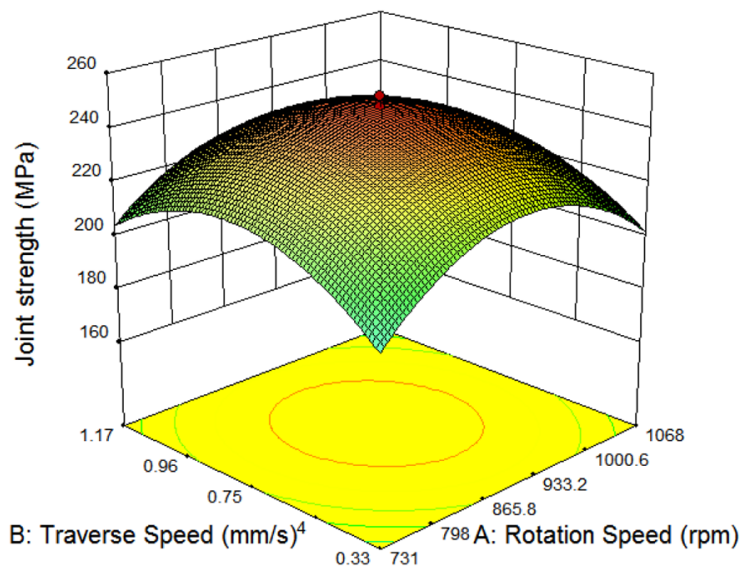

(a)

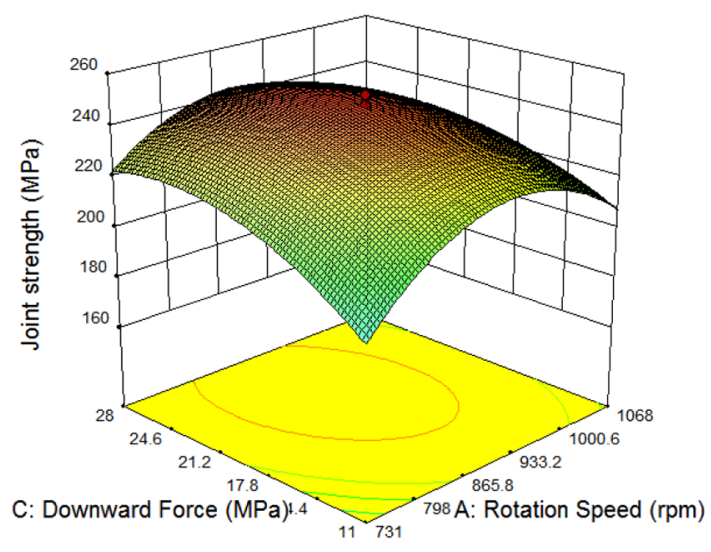

(b)

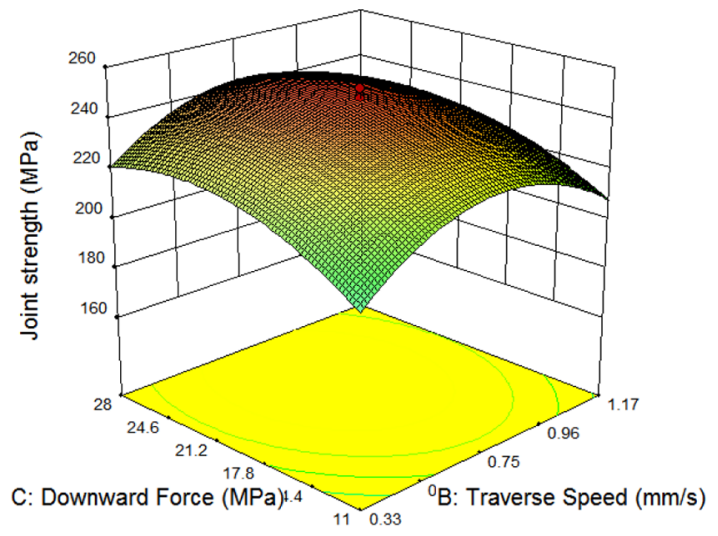

(c)

Fig. 3. Numerical analysis of tensile strength of joint with weld parameters. (a) Tool pass speed vs rotation speed (RSM). (b) Tool force vs rotation speed (RSM). (c) Tool force vs tool pass speed (RSM). 


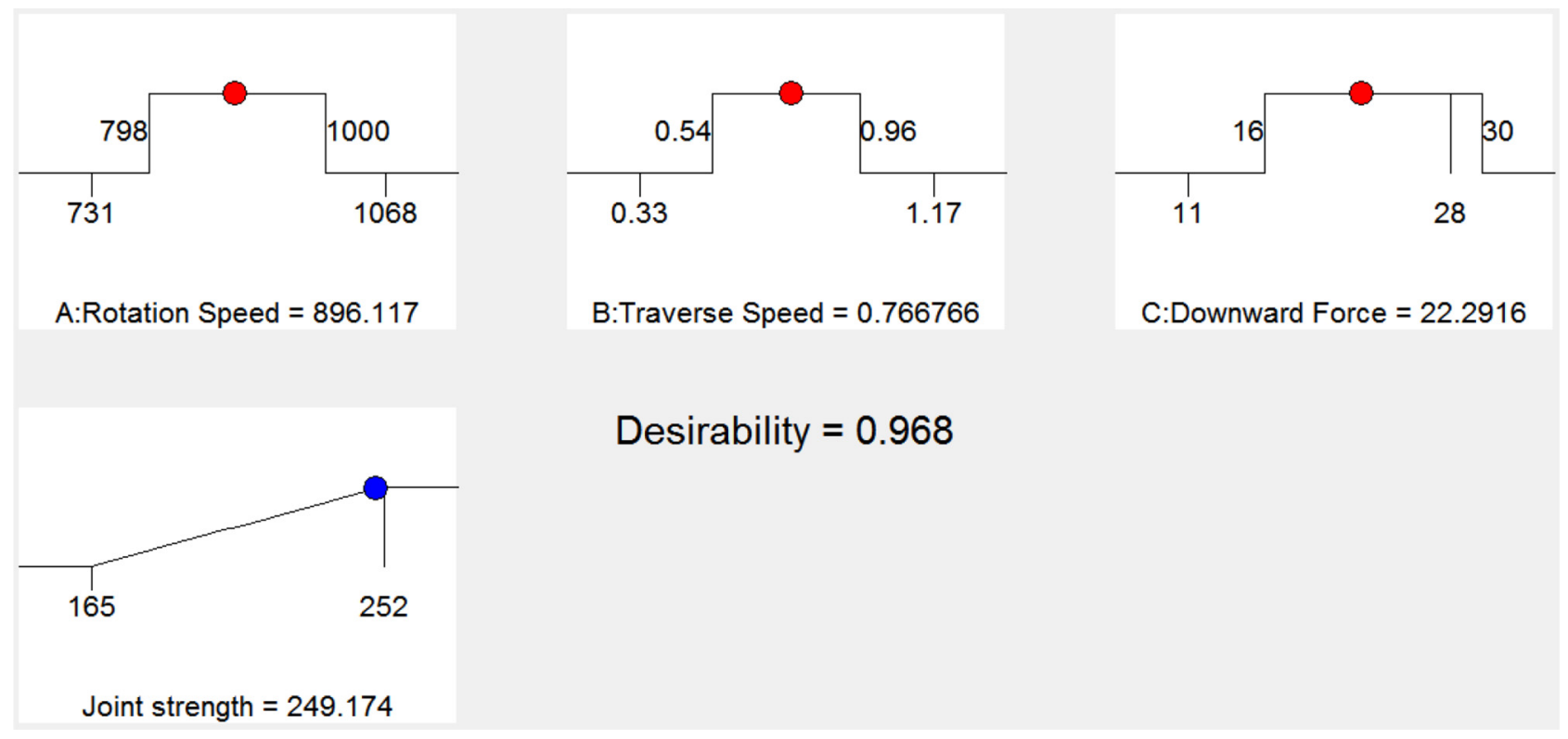

Fig. 4. The desirability of factors over response.

response, i.e., the tensile strength of the FSW joint was analyzed. The $3 \mathrm{D}$ response surfaces for the varying input parameters on the response are shown in Figure $3 \mathrm{a}-\mathrm{c}$.

It is observed that the two input parameters: tool rotation speed and tool pass speed are independent of each other in affecting the response as seen in Figure 3a. This signifies that while maintaining constant tool force, the tool rotation speed and tool pass speed have equal influence on the tensile strength of the produced FSW joint. It is observed that the tool force has a greater influence on the response compared to the tool rotation speed as seen in Figure $3 \mathrm{~b}$. The response varies by increasing the tool force and reducing the tool rotation speed. Figure $3 \mathrm{c}$ reveals that the tool pass speed is independent of the response and the tool force has greater influence, while the tool rotation speed is held constant.

The numerical analysis shows that by varying the tool pass speed between $0.54 \mathrm{~mm} / \mathrm{s}$ and $0.96 \mathrm{~mm} / \mathrm{s}$, the maximum tensile strength of the FSW joint can be attained. This is because the tool pass controls the even distribution of the weldment from the advancing side to the retreating side. However, when the tool pass speed is less than $0.54 \mathrm{~mm} / \mathrm{s}$, excessive deposition of weldment occurs. Improper joining can result when the tool pass speed is greater than $0.96 \mathrm{~mm} / \mathrm{s}$. This is because the weldment does not flow to the retreating side, leading to defects like particulate agglomeration, cracks, tunnels, wormholes, and kissing bonds. The numerical analysis shows that the tool force should be greater than $16 \mathrm{MPa}$ to get maximum tensile strength of $240 \mathrm{MPa}$.

\subsection{Optimization of weld parameters}

The three input parameters considered for this study were subjected to optimization for augmentation of the tensile strength of the FSW joint and also to minimize the weld defects. During the optimization of the input parameters, the tool rotation speed was set between $798 \mathrm{rpm}$ and $1000 \mathrm{rpm}$. Similarly, the tool pass speed was allowed to vary between $0.54 \mathrm{~mm} / \mathrm{s}$ and $0.96 \mathrm{~mm} / \mathrm{s}$. The tool force was varied between $16 \mathrm{MPa}$ and $30 \mathrm{MPa}$. The desirability using the optimized input parameters was 0.968 , which is closer to unity as shown in Figure 4.

After fixing the tool force as $22.3 \mathrm{MPa}$, the tensile strength of the FSW joint was sensitive to tool rotation speed and tool pass speed. In another case, it was observed that the tool rotation speed and the tool force were independent of the tensile strength of the FSW joint when the tool pass speed was set as $0.77 \mathrm{~mm} / \mathrm{s}$. These parameters increased the tensile strength to $249.174 \mathrm{MPa}$.

\subsection{Validation of developed model}

Table 6 shows the summarization of the optimized weld parameters obtained during this study. The experimentation was carried three times to validate the optimized model. It was found that by altering any one of the factors, the tensile strength of the joint diverged from the maximum value. This shows that any deviation in the factors or input variable from the optimized values will lead to the reduction of the tensile strength of the joint.

FSW joint was made on the MMC produced for this study as shown in Figure 5. The input parameters used for preparing the joint are tool rotation speed of $910 \mathrm{rpm}$, tool pass speed of $0.77 \mathrm{~mm} / \mathrm{s}$, and tool force of $22.33 \mathrm{MPa}$. The image shows that the frictional heat was sufficient to carry out the joint. The proportion between the indentation of the tool pin and the width of the tool shoulder in the FSW zone supports the claim. Onion rings were evenly placed in the joint. The metal protrusion was observed only at the 
Table 6. Developed model validation.

\begin{tabular}{|c|c|c|c|c|}
\hline \multicolumn{3}{|c|}{ Input parameters } & \multirow{2}{*}{$\begin{array}{l}\text { Tensile } \\
\text { strength }(\mathrm{MPa})\end{array}$} & \multirow{2}{*}{$\begin{array}{l}\text { Deviation from optimum } \\
\text { response value }(\mathrm{MPa})\end{array}$} \\
\hline $\begin{array}{l}\text { Tool rotation } \\
\text { speed }(\mathrm{rpm}) \\
\end{array}$ & $\begin{array}{l}\text { Tool pass } \\
\text { speed }(\mathrm{mm} / \mathrm{s})\end{array}$ & $\begin{array}{l}\text { Tool } \\
\text { force }(\mathrm{MPa})\end{array}$ & & \\
\hline 875 & 0.77 & 22.33 & 248.777 & 0.397 \\
\hline 910 & 0.77 & 22.33 & 248.996 & 0.178 \\
\hline 896 & 0.72 & 22.33 & 248.908 & 0.266 \\
\hline 896 & 0.81 & 22.33 & 248.947 & 0.227 \\
\hline 896 & 0.77 & 21.3 & 248.99 & 0.184 \\
\hline 896 & 0.77 & 23.3 & 248.988 & 0.186 \\
\hline
\end{tabular}

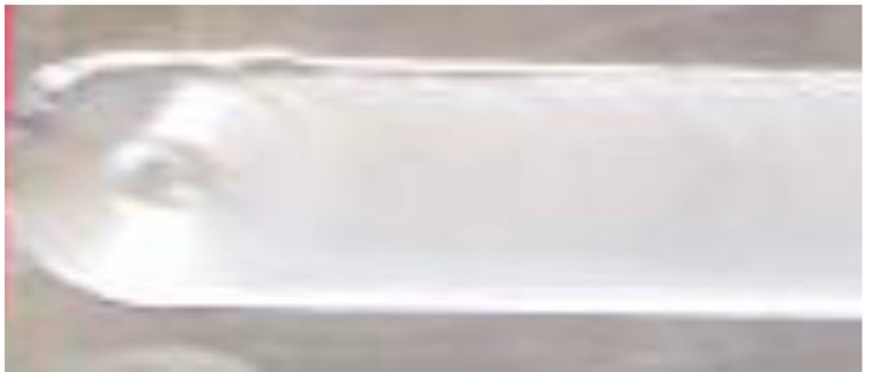

Fig. 5. FSW joint made on the MMC.

end of the joint. This phenomenon is attributed to the misalignment in the clamping provided at that end of the MMC. The maximum tensile test obtained after using the optimized weld parameters was $248.99 \mathrm{MPa}$.

\subsection{Optimized vs non-optimized weld parameters in FSW joints}

After the tensile test, the fractured surface of the FSW joints on the MMC (AA6061+10wt.\% $\mathrm{SiC}_{\mathrm{p}}$ ) was analyzed using Scanning Electron Microscope (SEM) to find the presence of defects. A comparison was made between SEM images obtained between the non-optimized specimen and its optimized counterpart as shown in Figure 6. The non-optimized FSW joint revealed cleavages and dimples in the fractured surface as shown in Figure 6a. This indicates that the MMC had both ductile and brittle characteristics. There were many defects like a tunnel, grain disbanding, particle agglomeration, microvoids, and micropores. The presence of fine grains and coarse grain structure in the fractured surface shows that these defects formed on the Thermo Mechanically Heat Affected Zone (TMAZ) of the FSW joints. The many defects in the FSW joints show that the weld parameters were not able to generate sufficient frictional heat energy required to obtain good quality joint.
The optimized FSW joint revealed dimples in the fractured surface on the TMAZ as shown in Figure 6b. This indicates that the grain restructuring occurred properly in the weld zone. The reformed grains in the TMAZ were smaller and rounded compared to their non-optimized counterpart. The defects such as particle agglomeration, tunnel defects, and microvoids did not occur in the FSW joint made using optimized weld parameters. However, defects like micropores and grain disbanding were present in the FSW joint. This shows that the optimization of the weld parameters contributed to the augmentation of the weld quality.

\section{Conclusion}

Friction stir welding was carried out on the metal matrix composite. The composite was made using aluminum alloy (AA6061) matrix and silicon carbide particles (10 wt.\%) reinforcements. Three different weld parameters, i.e., tool rotation speed (731-1068 rpm), tool pass speed $(0.33-1.17 \mathrm{~mm} / \mathrm{s})$, and tool force $(11-28 \mathrm{MPa})$ were considered during the welding process. By varying the weld parameters, the produced joints exhibited tensile strength ranging from $165 \mathrm{MPa}$ to $244 \mathrm{MPa}$. Defects such as tunnel, grain disbanding, particle agglomeration, microvoids, and micropores were observed in the produced joint. Numerical analysis using ANOVA, a three factorial central composite design was carried out to optimize the weld parameters to augment the strength of the joint and reduce the defects. The numerical analysis revealed that out of the three weld parameters, the tool force had a greater influence on the tensile strength of the joint. Optimization of the weld parameters revealed that tool rotation speed of $910 \mathrm{rpm}$, tool pass speed of $0.77 \mathrm{~mm} / \mathrm{s}$, and tool force of 22.33 MPa increased the tensile strength of the joint to $248.99 \mathrm{MPa}$. The joint thus produced was analyzed using the scanning electron microscope. The analysis revealed minimal defects like metal protrusion at the end of the joint, micropores, and grain disbanding. The number of defects was reduced and the tensile strength of the joint increased after using the optimized weld parameters. 


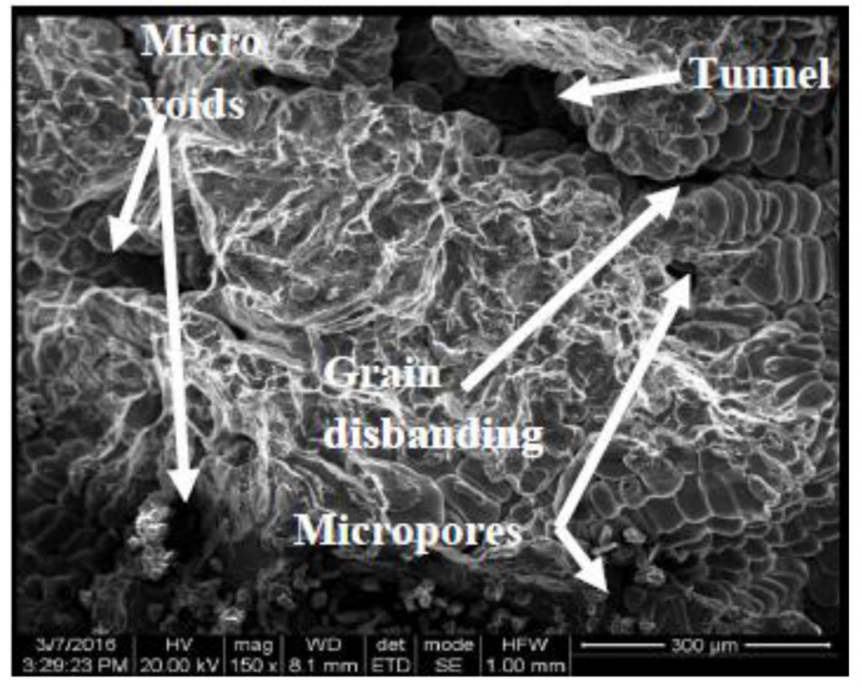

(a)

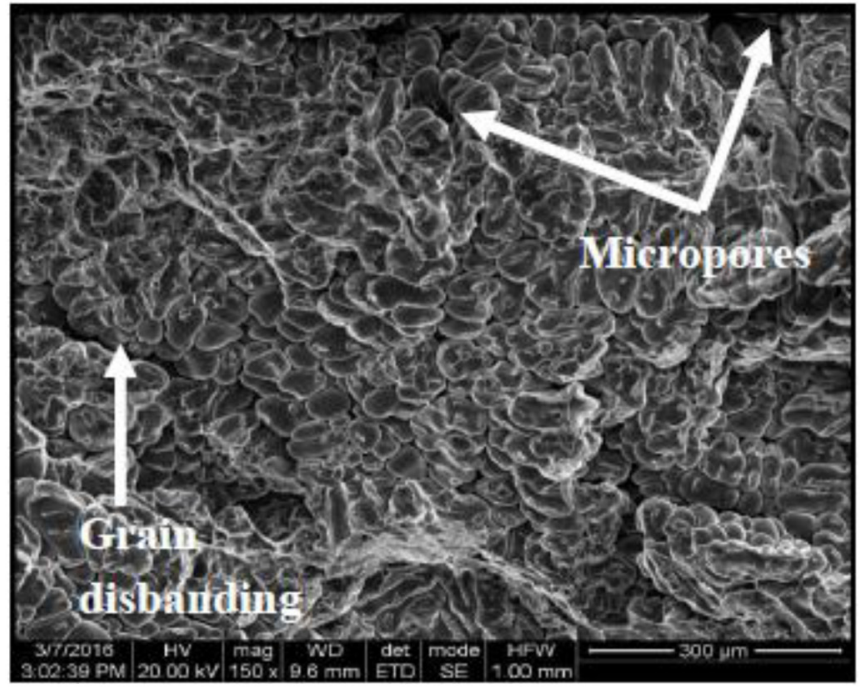

(b)

Fig. 6. SEM images of FSW joint. (a) Non-optimized. (b) Optimized.

\section{References}

1. I. Shigematsu, Y.J. Kwon, N. Saito, Dissimilar friction stir welding for tailor-welded blanks of aluminum and magnesium alloys, Mater. Trans. 50, 197-203 (2009)

2. Z.Y. Ma, Friction stir processing technology: a review, Metall. Mater. Trans. A Phys. Metall. Mater. Sci. 39A, 642-658 (2008)

3. V. Balasubramanian, A.K. Lakshminarayanan, The mechanical properties of the GMAW, GTAW and FSW joints of the RDE-40 aluminium alloy, Int. J. Microstruct. Mater. Prop. 3, 837-853 (2008)

4. E.F. Abo Zeid, Mechanical and electrochemical characteristics of solutionized AA 6061, AA6013 and AA 5086 aluminum alloys, J. Mater. Res. Technol. 8, 1870-1877 (2019)

5. J. Fahim, S.M.M. Hadavi, H. Ghayour, S.A. Hassanzadeh Tabrizi, Cavitation erosion behavior of super-hydrophobic coatings on Al5083 marine aluminum alloy, Wear 424-425, 122-132 (2019)

6. Z. Qi, H. Xiao, C. Yu, P. Xu, Z. Wu, Y. Zhao, Preparation, microstructure and mechanical properties of CP-Ti/ AA6061-Al laminated composites by differential temperature rolling with induction heating, J. Manuf. Process. 44, 133-144 (2019)

7. J. Joel, M.A. Xavior, Aluminium alloy composites and its machinability studies: a review, Mater. Today Proc. 5, 13556-13562 (2018)

8. C.M. Rao, K.M. Rao, Abrasive wear behavior of $\mathrm{TiB}_{2}$ fabricated aluminum 6061, Mater. Today Proc. 5, 268-275 (2018)

9. K.V. Bhaskar, S. Sundarrajan, B.S. Rao, K. Ravindra, Effect of reinforcement and wear parameters on dry sliding wear of aluminum composites: a review, Mater. Today Proc. 5, 5891-5900 (2018)

10. J.D.R. Selvam, I. Dinaharan, P.M. Mashinini, High-temperature sliding wear behavior of AA6061/fly ash aluminum matrix composites prepared using compocasting process, Tribol. Mater. Surfaces Interfaces 11, 39-46 (2017)
11. G.H. Kumar, M. Sreenivasan, S.M. Kumar, N.D. Raja, Microstructure characterization and mechanical properties of $\mathrm{Al}_{-} \mathrm{SiC}_{\mathrm{p}}$ composites, J. Mech. Res. Appl. 3, 1-7 (2011)

12. N.D. Raja, R. Velu, S.T. Selvamani, M. Vigneshwar, S. Divagar, Analysis of defects in friction stir welded metal matrix composite (AA6061 $+10 \%$ wt SiCp), Int. J. Appl. Eng. Res. 10, 68-71 (2015)

13. R.N. Dilip, R. Velu, S.T. Selvamani, Developing an empirical relationship to predict the maximum tensile strength on friction stir welded al based metal matrix composite joints produced by stir casting method, J. Chem. Pharm. Sci. 9, 1710-1713 (2016)

14. N.D. Raja, R. Velu, S.T. Selvamani, K. Palani Kumar, The comparative analysis of mechanical properties on MMC $\left(\mathrm{AA} 6061+\mathrm{SiC}_{\mathrm{p}} 10 \% \mathrm{wt}\right)$ before and after age hardening, Appl. Mech. Mater. 766-767, 276-280 (2015)

15. N. Dilip Raja, R. Velu, S. Divagar, M. Vigneshwar, S.T. Selvamani, Analysis on friction stir welded metal matrix composite produced by stir casting method, Int. J. Appl. Eng. Res. 10, 129-132 (2015)

16. G. Buffa, J. Hua, R. Shivpuri, L. Fratini, Design of the friction stir welding tool using the continuum based FEM model, Mater. Sci. Eng. A 419, 381-388 (2006)

17. Y.F. Sun, H. Fujii, The effect of $\mathrm{SiC}$ particles on the microstructure and mechanical properties of friction stir welded pure copper joints, Mater. Sci. Eng. A 528, 5470-5475 (2011)

18. S. Malarvizhi, V. Balasubramanian, Effect of welding processes on AA2219 aluminium alloy joint properties, Trans. Nonferrous Met. Soc. China (English Ed.) 21, 962-973 (2011)

19. L.M. Marzoli, A.V. Strombeck, J.F. Dos Santos, C. Gambaro, L.M. Volpone, Friction stir welding of an AA6061/Al2O3/20p reinforced alloy, Compos. Sci. Technol. 66, 363-371 (2006)

20. J. Fathi, P. Ebrahimzadeh, R. Farasati, R. Teimouri, Friction stir welding of aluminum 6061-T6 in presence of water cooling: Analyzing mechanical properties and residual stress distribution, Int. J. Light. Mater. Manuf. 2, 107-115 (2019) 
21. L. Curković, V. Rede, K. Grilec, A. Mulabdić, Hardness and fracture toughness of alumina ceramics, Proc. Conf. Mat. Proc. Fric. Wear. 40-45 (2007)

22. A.K. Lakshminarayanan, V. Balasubramanian, Tensile and impact toughness properties of gas tungsten arc welded and friction stir welded interstitial free steel joints, J. Mater. Eng. Perform. 20, 82-89 (2011)

23. K. Almadhoni, S. Khan, Review of effective parameters of stir casting process on metallurgical properties of ceramics particulate al composites, IOSR J. Mech. Civ. Eng. 12, 22-40 (2015)

24. T. Singh, S.K. Tiwari, D.K. Shukla, Friction-stir welding of AA6061-T6: the effects of $\mathrm{Al}_{2} \mathrm{O}_{3}$ nano-particles addition, Results Mater. 1, 1-12 (2019)

25. N. Gharaibeh, J.A. Al-Jarrah, S.A. Sawalha, Effect of pin profile on the mechanical properties of 6061 al alloy welded joints prepared by friction stir welding, Int. J. Mech. Appl. 6, 39-42 (2016)
26. M.O. Shabani, A. Mazahery, M.R. Rahimipour, M. Razavi, FEM and ANN investigation of A356 composites reinforced with $\mathrm{B}_{4} \mathrm{C}$ particulates, J. King Saud Univ. - Eng. Sci. 24, 107-113 (2012)

27. G. Padmanaban, V. Balasubramanian, Selection of FSW tool pin profile, shoulder diameter and material for joining AZ31B magnesium alloy - an experimental approach, Mater. Des. 30, 2647-2656 (2009)

28. J.S. Hong, K.H. Lee, C.H. Lee, The frame optimization and validation of resistance spot welding gun, Int. J. Simul. Multidiscip. Des. Optim. 11, 1-9 (2020)

29. M. Boukraa, M. Aissani, N. Lebaal, D. Bassir, A. Mataoui, N.T. Ighil, H. Yue, Effects of boundary conditions and operating parameters on temperature distribution during the friction stir welding process, IOP Conf. Ser. Mater. Sci. Eng. 1140, 1-8 (2021)

Cite this article as: N. Dilip Raja, R. Naren Shankar, Optimization of friction STIR welded AA6061 + SiCp metal matrix composite to increase joint tensile strength and reduce defects, Int. J. Simul. Multidisci. Des. Optim. 12, 28 (2021) 